\title{
Should cisapride have been "blacklisted"?
}

The recent decision by the Committee on the Safety of Medicine effectively to "blacklist" cisapride for use in neonates has led to considerable debate. The following is intended as a contribution to that debate.

\section{Indications for the use of cisapride}

In mild gastro-eosophageal reflux disease (GORD) parental reassurance and dietary manipulation is the most appropriate course of action. In moderate or severe GORD, when medication is thought to be necessary, cisapride is considered to be the most appropriate drug. ${ }^{1}$ Although it is recognised that cisapride does not consistently show an improvement in all the parameters measured, it consistently shows improvement in at least some of them, most of the time. ${ }^{2}$ Lack of similar data for the efficacy of domperidone, metoclopramide, and erythromycin precludes their use as first line agents for GORD. ${ }^{3}$ Published findings on the efficacy of cisapride in the treatment of motility related gastrointestinal disorders in premature infants is not entirely clear. ${ }^{2}$ The impending studies of cisapride in the USA should clarify the issue. Cisapride is useful in several other conditions, such as chronic respiratory disease caused by GORD, oesophagitis, functional dyspepsia and postoperative ileus. ${ }^{23}$

\section{Risks associated with cisapride}

Cisapride is known to prolong the QTc interval. ${ }^{3-5}$ At therapeutic doses in children, however, there is no direct association between serum concentrations and QTc prolongation. Even in overdose situations the drug has a remarkable safety profile. ${ }^{3-6}$

Events which also predispose towards prolongation of the QTc interval must be avoided-that is, concurrent administration of macrolide antibiotics and azole antifungals, as well as hypokalaemia and hypomagnesaemia. In these situations there is a real risk that QTc prolongation may have an adverse clinical outcome such as torsade des pointes or a clinically significant degree of heart block. ${ }^{3}$

\section{Safety data}

Cisapride has been used in 140 million patient treatments of which $18 \%$ (25.2 million) were in the age group 0-1 years ${ }^{7}$ and $9 \%$ (12.6 million) in the age group 1-20 years. There was not a single report of a death in a previously healthy child taking an appropriate dose of cisapride. ${ }^{3}$ The single most worrying feature of cisapride is its potential to prolong the QT interval. However, the fact that there is no agreed method for measuring the normal QTc interval, nor is there an agreed normal range in neonates and premature infants, makes any comment on QTc prolongation rather suspect. Although normal ranges in infants have been published, ${ }^{8}$ those in premature infants are unknown. A review of published findings suggests that a QTc beyond $0.5 \mathrm{sec}-$ onds is prolonged, ${ }^{8}$ implying that cisapride should be withheld in these cases. All reported cases of the arrhythmia torsade de pointes were associated either with concomitant administration of a macrolide antibiotic, or a cisapride overdose, or both. ${ }^{35}$

From post-marketing experience it can be concluded that cisapride can be used safely at a maximal dose of 0.8 $\mathrm{mg} / \mathrm{kg} /$ day. It is this dose that we feel should be recommended.

Safety data for fundoplication for intractable GORD showed the "accepted" risk of death was $0.07 \%$ in the group of "normal" children and $0.8 \%$ in the group of chil- dren who were neurologically impaired. ${ }^{9}$ The equivalent figures of risk of death from the use of cisapride in the normal population are significantly lower than that- 1 in 250000 being a conservative estimate.

\section{Pharmacokinetic data}

In adults a dose of $10 \mathrm{mg}$ four times a day gives a plasma concentration of $48-76 \mathrm{ng} / \mathrm{ml}^{10}{ }^{10}$ (According to company data on a larger cohort of patients, plasma concentrations range from $14.1-192 \mathrm{ng} / \mathrm{ml})$. In 66 premature infants a similar profile $(7.1-170 \mathrm{ng} / \mathrm{ml})$ was achieved with a dose of $0.2 \mathrm{mg} / \mathrm{kg}$ three to four times a day (unpublished observations). In spite of the immaturity of the drug metabolising capacity and the renal function, the plasma concentrations of cisapride in premature infants appeared very similar to those in term infants, children, and adults. ${ }^{11}$

In 41 infants ranging from 3-51 weeks a similar dose produced plasma concentrations not dissimilar to those of the premature infants, albeit with a lower mean: 42.6 (36.6) $\mathrm{ng} / \mathrm{ml}$ (range $0-155 \mathrm{ng} / \mathrm{ml}) .^{12}$ Thus at the appropriate dose, plasma cisapride concentrations in premature and term infants, as well as in children, were within the therapeutic and safe range observed in adults. (Company data suggest that plasma concentrations in older children follow a similar pattern.)

\section{Precautions}

All premature infants ( 36 weeks of gestation or less) should have an ECG before starting treatment with cisapride; this should be repeated three days later. This recommendation is based on the fact that premature infants treated with cisapride are thought to be specifically at risk of QTc prolongation. Furthermore, it is very important to ensure that electrolyte status is normal.

For term infants we do not feel it necessary to check an ECG before starting treatment with cisapride unless there are indications of congenital problems (prolonged QT).

Concomitant administration of macrolide antibiotics such as erythromycin, clarithromycin, and troleandromycin, as well as azole antifungal agents are contraindicated.

\section{Conclusions}

Cisapride is safe, but can potentially be associated with serious side effects if used inappropriately. We suggest that the Committee on the Safety of Medicine re-evaluate their guidance on cisapride use in infants and children, as has already been suggested. ${ }^{12}$ Trials shortly to begin in the USA should be used to finalise data on the drug's efficacy and safety. An appropriate license for use in children should be obtained in the UK as soon as possible.

Cisapride should not be used in the dose range $>0.8$ $\mathrm{mg} / \mathrm{kg} /$ day except under strict specialist guidance. Safety monitoring with an ECG 2 to 3 days after starting treatment should be mandatory. Cisapride should not be used in conjunction with macrolide antibiotics and azole antifungals. Hypokalaemia and hypomagnesaemia must be corrected before treatment is started and electrolytes should be checked during treatment. Further information is required about the excretion in breast milk of other proarrhythmic drugs such as antihistamines and antidepressants in case drugs given to breast feeding mothers may affect their infants. Premature infants should also have an ECG checked routinely before treatment with cisapride as well as three days after starting treatment. 
We thank the following who contributed to the discussions that formed the basis for our report: Abrahamson S Biswas, I Balfour-Lynn, A Bedford Russell, M Brueton, I Costello, S Craig S, M Elsawi, J Fell, J Hawdon, I Kovar, N Madden, S Mitton, B Planer, R Rivers, E Smith S Spielberg, P Sullivan, M Thomson, J Till, R Tubman, O C Ward.

Dr Spielberg is employed by Celag Johnson as their chief clinical pharmacologist and attended as a representative for the company. The meeting was not sponsored and all participants attended at their own expense.

M MARKIEWICZ

Imperial College School of Medicine at Chelsea $\mathcal{E}$ Westminster Hospital, 369 Falham Road,

London SW10 9NH

$A Z-V U B$

Y VANDEN PLAS

Department of Paediatrics,

Laarbeeklaan 101,

1090 Brussels,

Belgium

1 Vandenplas Y, Ashkenazi A, Belli D, Boige $\mathrm{N}$ et al. A proposition for the diagnosis and treatment of gastro-oesophageal reflux disease in children: a report from a working group on gastro-oesophageal reflux disease. Working Group of the European Society of Paediatric Gastro-enterology and Nutrition (ESPGAN). Eur f Pediatr 1993;152:704-11
2 Vandenplas Y. Clinical use of cisapride and its risk-benefit in paediatric patients. Eur f Gastroenterol Hepatol 1998;10:871-81.

3 Vandenplas Y, Belli DC, Benatar A, et al. The role of cisapride in the treatment of pediatric gastroesophageal reflux. F Pediatr Gastroenterol Nutr 1999;28:518-28.

4 Bedford TA, Rowbotham DJ. Cisapride. Drug interactions of clinical significance. Drug Safety. 1996;15:167-75.

5 Shulman RJ, Boyle JT, Colletti RB, et al. The use of cisapride in children. $\mathcal{F}$ Pediatr Gastroenterol Nutr 1999;28:529-33.

6 Volmer PA. Cisapride toxicosis in dogs. Vet Hum Toxicol 1996;38:118-20.

7 Ward RM, Lemons JA, Molteni RA. Cisapride: a survey of the frequency of use and adverse trials in premature newborns. Pediatrics 1999;103:469-72.

8 Schwartz PJ, Montemerlo M, Facchini M, et al. The QT interval throughout the first 6 months of life: A prospective study. Circulation 1982;66:496-501.

9 Fonkalsrud EW, Ashcraft KW, Coran AG, Ellis DG, Grosfeld JL, Tunell WP, Weber TR. Surgical treatment of gastroesophageal reflux in children: a combined hospital study of 7467 patients. Pediatrics 1998;101(3 Pt 1): a combine $419-22$.

10 Holloway RH, Downton J, Mitchell B, Dent J. Effect of cisapride on postprandial gastro-oesophageal reflux. Gut 1989;30:1187-93.

11 Feenstra A, Benatar A, De Craene T, Vandenplas Y. Cisapride plasma levels and effects on QTc interval and heart rate. 7 Pediatr Gastroenterol Nutr 1999;28:553(A).

12 Lander A. The risks and benefits of cisapride in premature neonates, infants, and children. Arch Dis Child 1998;79:469-70. 